\title{
Strategic Management and Ranching: Successfully Planning for the 21st Century
}

\section{By Barry H. Dunn and Kimberly C. McCuistion}

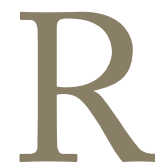

anchers are, by tradition, training, and perhaps even by their very nature, excellent operational managers. Evidence of this is clear. In 2007, our nation's beef cattle industry produced record amounts of beef with $70 \%$ of the cattle of a few short decades ago. Ranches that have developed hunting and wildlife enterprises not only have added to their bottom line, but have expanded the boundaries of conservation management of ranch and rangeland resources. However, the world around the ranching industry continues to change at accelerating rates. The marketplace for goods, services, and products produced on or provided by ranches and rangelands is dramatically different than it was just a few short years ago. Public policy concerning everything from private property rights to estate taxes seems to be, at best, a moving target. During the last 40 years, businesses of all types and sizes have successfully dealt with similar conditions of change and instability with the use of a proven and successful business process known as strategic management. The cornerstone of strategic management is strategic planning.

Ranching is a highly capitalized business. ${ }^{1}$ Variations in weather alone create uncertainty. Because of these and other facets of the ranching business, it is of critical importance in a planning process to determine if potential strategies derived through strategic planning will be successful across multiple events important to a rancher's business, commonly referred to scenarios. Some of these scenarios or events might seem unrelated to the situation that the strategy was developed to address. Scenario planning, then, is a way of testing strategies against the dynamic world around the ranch. In the complex world of ranching, doing the due diligence of testing prior to implementation is a wise idea. An innovative tool called scenario planning can be incorporated into the strategic management process to do just that, test possible strategies against likely future scenarios. Additional resources about strategic management can be found in the sidebar.

The following discussion describes both the strategic planning process and how scenario planning can be used to evaluate potential strategies. Two of the articles that follow this one, the first by Austin Anderson and Kimberly McCuistion and the second by Doug Wilmeth, Brian Bertelsen, and Dan Probert, provide example strategies for consideration by ranchers as they look to the future in a strategic planning process. The third, by James Mintert, offers an excellent example of a developing scenario that will be felt across all of agriculture and influence the use of rangeland resources. Together, the three articles will be used as examples of the power of developing strategies for ranch and rangeland management, and testing their potential success against a dynamic situation in the world around us.

\section{The Process of Strategic Management}

Table 1 outlines the strategic management process recommended by the King Ranch Institute for Ranch Management for use by ranchers and rangeland managers. ${ }^{2}$ It includes five basic stages with ten fundamental steps. A detailed description of the entire process is outlined in the workbook published in 2007 by Gates and coworkers. ${ }^{2}$ The focus of this article will be determining strategies to achieve a ranch's vision, scenario planning for the ranch, and merging strategy with scenario planning. An assumption will be made that the process of developing a vision for the future of a ranching operation has been successfully completed. How to actually put a plan into action and measuring success will not be discussed in this article. This process is outlined in the workbook published in 2006 by Dunn and coworkers. ${ }^{3}$ 
Additional references and resources pertaining to strategic management

Additional references

Carlock, R. S., and J. Ward. 2001. Strategic planning for the family business. New York, NY, USA: Palgrave. 256 p. ISBN 0-33394-731-2.

JAFFE, D. T. 1991. Working with the ones you love: strategies for successful family business. Emeryville, CA, USA: Conari Press. 284 p. ISBN 0-94323-322-4.

Kaplan, R. S., and D. P. Norton. 2004. Strategy maps. Boston, MA, USA: Harvard Business School Publishing Corporation. 39 p. ISBN 1-59139-134-2.

Nagler, A., C. T. Bastian, J. P. Hewlett, and W. R. RANDOLPH. 2007. Risk management for ag families: evaluation of an integrated educational program for producers on the Northern Plains. Journal of Extension 45:1-9.

Shadbolt, N., and S. Martin. 2005. Farm management in New Zealand. New York, NY, USA: Oxford University Press. 408 p. ISBN 0-19558-389-2.

Shadbolt, N. M. 2007. The balanced scorecard: a strategic management tool for ranchers. Rangelands 29(2):4-9.

Reference websites
Using the balanced scorecard for ranch planning and man-
agement: setting strategy and measuring performance.
Agbiopubs.sdstate.edu/articles/EC922.pdf
Strategic Business Planning for Commercial Producers
www.agecon.purdue.edu/extension/sbpcp/
Strategic Management for Farm Families
www.extension.iastate.edu/ames/smff.htm
Strategic Management Society
www.smsweb.org/publications/journal/index.html
The Cattleman
www.texascattleraisers.org/cattlemanbackissues.asp
University of Kansas Community Tool Box
ctb.ku.edu/tools/developstrategicplan/index.jsp

There are real and important differences between strategies, tactics, and operational chores. Each is of critical importance to a ranching operation. However, people unfamiliar with these planning processes can find them confusing. Strategies should be thought of as plans developed from a 30,000-ft view looking down at the ranch. They are the "big picture" type plans. Tactics are the plans that make strategy work. They are the implementation phase of strategic management. Operational planning and work are the daily tasks that are designed to complete tactics. An example of a strategy could be to improve wildlife habitat in order to add a hunting enterprise to a ranching operation. A tactic
Table 1. The strategic planning process recommended by the King Ranch Institute for Ranch Management

\section{Stage 1: Charting the Course: Creating the Vision}

Step 1: Assess current situation and inventory of ranch resources

Step 2: Conduct Strengths, Weaknesses, Opportunities, and Threats (SWOT) analysis

Step 3: Establish a vision for the ranch

Stage 2: Determining Strategies to Achieve the Ranch's Vision

Step 4: Incorporate "gap" analysis

Step 5: Identify alternative strategies to close the gap

\section{Stage 3: Scenario Planning For the Ranch \\ Step 6: Describe multiple scenarios \\ Step 7: Select and evaluate most probable scenarios \\ Stage 4: Merging Strategies and Scenario Planning}

Step 8: Choose strategies with highest likelihood of success

\section{Stage 5: Putting the Plan into Action and} Measuring Success

Step 9: Implementation of the strategic plan

Step 10: Monitor performance with the balanced scorecard

Details can be found in Gates et al. 2007. ${ }^{2}$

designed to accomplish that strategy might be using flexible stocking rates. An example of an operational task could be timely destocking during drought.

\section{Determining Strategies for Achieving Your Ranch's Vision \\ "Operational and tactical management are essential skills on all ranches and must be mastered. However, the ranch team must also deliver to the vision that they and their family aspire to. And using strategic planning is essential to accomplishing that." (Nicola Shadbolt)}

The assumption, then, is that the rancher or rangeland manager not only has excellent operational skills but also has an envisioned future of where the ranching operation is headed. The responsibility of the ranch manager then is to develop strategies to achieve the vision. A relatively simple tool to aid in the development of strategies is a business tool known as GAP analysis. A GAP analysis is a test between the current situation and the vision. A GAP analysis needs to answer the following questions: ${ }^{2}$ 
1) How does your vision compare with the current status of the operation?

2) How does the desired vision fit with available resources?

3) How does the business operation measure up to current industry benchmarks?

4) How different is the current culture from the required one?

An example of a gap might be that in order to generate more net income, a hunting operation is being considered. However, the condition of the ranch's rangeland currently will not support wildlife populations. Another might be that the vision of the ranch is to expand, but an analysis of the ranch's financial situation indicates that the present cash flow does not support the purchase of additional pastureland.

Once gaps have been identified, the rancher needs to identify strategies that might be undertaken to close the gaps to reach the ranch's vision. But care must also be taken. There are important questions to be asked. How large is the difference between the current state and the desired vision? Is closing the gap achievable? If so, are additional resources required, and are they available and affordable? The answers to these questions might lead to a modification of the vision. Or perhaps the time frame must be extended. It might be a matter of reallocating resources on the ranch. Creativity and flexibility are key components of this part of the exercise. There is a fine line between coming up with achievable creative solutions and unrealistic ideas. However, doing nothing will not change the status quo. A list of possible strategies to close the gap, ranked by achievability, is the goal of this stage.

Two articles in this issue (the first by Anderson and McCuistion, and the second by Wilmeth et al.) offer excellent examples of strategies to consider, and the depth of understanding necessary, before a strategy should be seriously considered for implementation in a strategic management plan.

\section{Scenario Planning for the Ranch}

A metaphor for the importance of scenario planning can be found with automotive images. A driver of a car or truck watches three basic things: the rear view mirror, the gauges on the dashboard, and the windshield. In ranch management, the rear view mirror represents trend analysis and looking at past performance. The gauges on the dashboard represent monitoring current activity. The front windshield represents looking forward at changing landscapes of the environment around the ranch business. The smallest of the three images is the rear view mirror. The next image is the gauges on the dashboard. The largest view is provided by the windshield. Certainly in the current dynamic business environment surrounding ranching, looking forward is of critical importance.
The goal of scenario planning is to look forward and identify a reasonable number of scenarios that have the potential to dramatically impact a ranching operation. It begins with a brainstorming session. It requires a deep awareness of the activities in politics, business, and the community that might have an impact on the ranch. However, the final list to consider should be limited to three to five scenarios. More than that and the process can become overwhelming.

An example of a critical scenario that ranchers should consider in the planning process is described in the article in this issue of Rangelands by Mintert. Other examples of current scenarios worthy of serious consideration by ranchers include the price of oil and its impact on ranching operations, commodity price volatility, and the availability and cost of skilled labor. Examples of events or trends that probably shouldn't be considered as scenarios are highly political situations such as elections or movements in speculative financial markets. Although they might prove to be important, their outcomes are not only difficult to predict, but they are so complex that predicting their impact on a single ranch is very difficult.

\section{Merging Strategies with Scenarios}

The final step in this discussion of strategic management is to test the probability of success of the strategies developed in GAP analysis against the scenarios that the manager feels are most likely to impact the ranch. Table 2 is an example of the relatively simple matrix used to do this. Scenarios are listed across the top. For this example, four were chosen: 1) the impact of the emerging ethanol business, 2) the increasing price of oil and its impact on the ranching operations, 3) volatility in the prices of commodities, and 4) the availability and cost of skilled labor.

The two strategies used as examples in the first column of Table 2 are 1) managing rangeland for both wildlife and livestock, and 2) selling ranch livestock through a valuebased marketing alliance. Following across their respective rows, the manager makes a subjective evaluation if the strategy will be successful under the conditions created by each scenario. If the manager feels that the likelihood of success is high, a plus sign is placed in the corresponding cell of the matrix. If the manager feels that the strategy will not be successful given the impact of the scenario, a minus sign is placed in the cell. If the success of the strategy is not impacted either way by the scenario, a zero is placed in the cell.

In the example used in Table 2, the strategy of managing rangeland for both wildlife and livestock received a plus sign under each scenario because it should be successful regardless of the ethanol industry, increasing oil prices, price volatility of commodities, and is not impacted by the availability or cost of labor. Participation in a value-based marketing program could be evaluated similarly, except perhaps on the labor scenario. If source, age, and process verification of the 


\begin{tabular}{|c|c|c|c|c|}
\hline & Scenario 1 & Scenario 2 & Scenario 3 & Scenario 4 \\
\hline & Emerging ethanol & High oil prices & $\begin{array}{c}\text { Commodity price } \\
\text { volatility }\end{array}$ & $\begin{array}{c}\text { Increasing labor } \\
\text { costs }\end{array}$ \\
\hline \multicolumn{5}{|l|}{ Strategy 1} \\
\hline Cattle and wildlife & + & + & + & + \\
\hline \multicolumn{5}{|l|}{ Strategy 2} \\
\hline New market & + & + & + & - \\
\hline
\end{tabular}

cattle operation requires increased levels of skilled labor, then it might not be as successful if the supply of skilled labor decreases and its cost increases. So in this example, that strategy received plus signs under the ethanol, price of oil, and price volatility scenarios, but a minus sign under labor. Although somewhat subjective, this process can have unexpected benefits because of its thought-provoking nature.

When evaluating the results of this relatively simple exercise, if a strategy has a majority of positive signs or zeros under the scenarios, it most likely will move a ranch towards its envisioned future. Correspondingly, if there are a large number of minuses for a strategy, then caution should be taken when considering implementation. Or, perhaps the ranch manager can make changes that mitigate the negative impacts and proceed. The point is that not every strategy a manager is considering will be successful in the dynamic world in which we live, not necessarily because of bad management, but because of conditions created in the world around the business that are hard to anticipate. Successfully merging strategic planning with scenario planning can mitigate the risk of failure or negative consequences from the implementation of a particular strategy.

\section{Summary and Concluding Thoughts}

We live in a highly technical and complex world. In comparison, the processes of GAP analysis, developing strategies to close the gaps, scenario planning, and merging strategies with scenarios to help determine future success, might seem very simple and even subjective. But management is both art and science. Managerial intuition can be a powerful tool. The processes described above rely on that intuition. They also require constant monitoring of the world around the ranch. Complexity does not always positively relate to success. Simplicity does not either, but simple straightforward management tools such as strategic planning and scenario planning not only have a proven track record of success, but can easily be applied to the management of ranches and rangelands.

\section{References}

1. Dunn, B. H., R. J. Pruitt, E. D. Hamilton, and D. Griffith. 2005. Factors affecting profitability of the cow-calf enterprise in the Northern Great Plains. 2005 Beef Report. Brookings, SD, USA: South Dakota State University Agriculture Experiment Station. 6 p.

2. Gates, R. N., B. H. Dunn, J. Davis, and A. Arzeno. 2007. Strategic and scenario planning in ranching: managing risk in dynamic times. Brookings, SD, USA: South Dakota State University. EC9242. $44 \mathrm{p}$.

3. Dunn, B. H., R. N. Gates, J. Davis, and A. Arzeno. 2006. Using the balanced scorecard for ranch planning and management: setting strategy and measuring performance. Brookings, SD, USA: South Dakota State University. EC922. 32 p.

4. Shadbolt, N. M. 2006. Presentation at the 2006 HOLT CAT $^{\circledR}$ Symposium on Excellence in Ranch Management; October 2006; Kingsville, TX, USA.

Authors are Associate Professor, King Ranch Institute for Ranch Management, Texas A\&M University-Kingsville, and Executive Director of the King Ranch Institute for Ranch Management, Kingsville, TX 78363, USA, barry.dunn@tamuk. edu (Dunn); and Assistant Professor, King Ranch Institute for Ranch Management, Texas AEM University-Kingsville, Kingsville, TX 78363, USA (McCuistion). 